\title{
Impact of Injection Timing on the Performance of Single Cylinder DI Diesel Engine Fueled with Solid Waste Converted Fuel
}

\author{
Nagaraj R. Banapurmath ${ }^{1 *}$, Sudershan B. Gadwal ${ }^{2}$, M. A. Kamoji ${ }^{3}$, P. B. Rampure ${ }^{4}$, S. V. Khandal 5 \\ 1 School of Mechanical Engineering, KLE Technological University, B. V. B. College of Engineering and Technology, \\ Vidyanagar, 580031 Hubballi, INDIA \\ ${ }^{2}$ Department of Mechanical Engineering, A. G. Patil Institute of Technology, Solapur, INDIA \\ ${ }^{3}$ Department of Mechanical Engineering, KLE Dr. M.S.S. College of Engineering and Technology, Belagavi, Karnataka, \\ INDIA \\ ${ }^{4}$ Department of Mechanical Engineering, KLE College of Engineering and Technology, Chikodi, Karnataka, INDIA \\ ${ }^{5}$ Department of Mechanical Engineering, KLE Technological University, B. V. B. College of Engineering and Technology, \\ Hubballi, Karnataka, INDIA
}

*Corresponding Author: nrbanapurmath@gmail.com

Citation: Banapurmath, N. R., Gadwal, S. B., Kamoji, M. A., Rampure, P. B. and Khandal, S. V. (2018). Impact of Injection Timing on the Performance of Single Cylinder DI Diesel Engine Fueled with Solid Waste Converted Fuel. European Journal of Sustainable Development Research, 2(4), 39. https://doi.org/10.20897/ejosdr/3914

Published: October 4, 2018

\begin{abstract}
The transfer of waste plastics has turned into an incredible test to the waste management system and because of urbanization and industrialization has prompted consumption of petroleum derivative for energy prerequisite in different areas. The answers for these issues could be overwhelmed by legitimate use of waste plastics as fuel. The paper depicts a correlation of the utilization of pyrolysis oil which is plastic pyrolysis oil (PPO) and diesel in the appraisal of engine execution. Pyrolysis oil is utilized as fuel to check the execution on one-cylinder with water cooled diesel engine. From the investigation, it was found that without engine adjustment, the PPO offers better engine execution with advancement of Injection timing (IT) and could enhance execution by modifying engine.
\end{abstract}

Keywords: plastic pyrolysis oil, engine performance, injection timing, injection pressure

\section{INTRODUCTION}

Diesel engine finds wide applications in transportation, power and agriculture sector. Petroleum fuels used for such applications are get depleting at a faster rate simultaneously the emission from these application is of great concern. This has intensified the search for alternative fuels for internal Combustion engines. Developing the alternate energy sources, for example, biomass, hydro power, geothermal energy, wind energy, sun oriented energy, and atomic energy has been engaged by humanity over the previous decade because of the non-renewable energy source emergency. The engaged advancements incorporate bio-diesel lipid inferred biofuel, bio-ethanol, oil extracted from solid wastes, pyrolysis, gasification, dimethyl ether, and bio gas (Rutz and Janssen, 2007). Alternative energy derived from non-depleted resources is sustainable in the long term and still leaves gaps for research. Many researchers have studied the energy recovery from non-biodegradable wastes polymers such as municipal plastic wastes, waste tyres, etc. (Scheirs and Kaminsky, 2006; Lin and Wang, 2004; Murugan et al., 2008; Mani and Nagarajan, 2009; Mani et al., 2009). The method of energy recovery from plastic wastes does not give only a new 
alternative energy source but it is also a method of non-biodegradable waste management. Thus, this is one of the most interesting and satisfactory methods for current and future situations. Pyrolysis is a process of thermal degradation of material in absence of oxygen and it has become an option of waste-to-energy technology to yield bio-fuel. Waste plastic oil is examined in this exploration as they are the available technology. The upside of the pyrolysis procedure is its capacity to deal with unsort and grimy plastic. Waste plastics generated from various sources are collected, organized, cleaned and dried. Pyrolysis offers pollution free process as it is carried out in the absence of oxygen generally air (Scheirs and Kaminsky, 2006).

Diesel engines are broadly utilized as prime movers in transport industry, in power generation sector and widely in farm sectors. Due to their high efficiency compared to their counter parts petrol engines and other types of prime movers like gas turbines. Diesel engines are generally utilized for the previously mentioned applications because of their straightforward and strong mechanical structure, low fuel cost, high dependability and sturdiness, and high energy to weight proportion as detailed by Lin and Wang (Lin and Wang, 2004). Subsequently, because of its one of a kind blend of energy efficiency, power, unwavering quality, and strength, diesel innovation assumes a crucial part in car and power generation applications. Different work has been carried out on Compression ignition (CI) engine operated with PPO and observed that it can be a substitute to diesel (Murugan et al., 2008; Mani and Nagarajan, 2009). Pyrolysis oils are a complex mixture blend of C5-C20 organic compound. Unsorted plastic yield PPO with high chlorine content (Mani et al., 2009; Demirbas, 2004). The investigation as far as chemical process, production and feasibility assessment of both pyrolysis oils are done in past research (Islam et al., 2011; U.S.EPA, 2010). There is no exploration about the utilization of the oil regarding execution of plastic oil on diesel under the impact of injection timing with different parameters length and can possibly supplant the petroleum derivative.

This paper describes the utilization of waste solid fuel obtained from pyrolysis in the assessment of single cylinder DI diesel with different fuel injection timing.

\section{MATERIAL AND METHODS}

\section{Pyrolysis Oil}

Feedstock used is the principle factor that decides the properties of pyrolysis oil. Plastic pyrolysis advance technologies are available in India. The feedstock pre-process is one of the principle components to evaluate the likelihood of the innovation. Organizing and cleaning is required for plastic process. Physical and chemical properties of plastic oil are examined and then utilized the oil in diesel engine.

\section{Plastic Pyrolysis Oil}

Because of their lightweight, durability, combined with a quicker rate of production and design flexibility, the plastics are utilized in whole range of modern and household territories. Plastics are created from oil derivatives and are made principally out of hydrocarbons yet in addition contain added substances, for example, cancer prevention agents, colorants and different stabilizers (Hamid et al., 1992; Williams and Williams, 1990; Williams and Williams, 1997). Transfer of the thrown plastics represents a great danger to the earth and powerful strategy has not yet been actualized. Because of non-biodegradable nature, the plastic waste contributes altogether to the issue of waste administration. As indicated by an across the nation review which was led in the year 2000, around 6000 tons of plastic waste were produced each day in India, and just $60 \%$ of it was reused and remaining $40 \%$ not available for reuse. Today around 129 million tons of plastics are brought to market every year and everywhere throughout the world, out of which 77 million tons are delivered from oil (Phong et al., 2001). In India alone, the requirement of plastics is around 8 million tons for every year. More than 10,000 metric tonnes/day are produced in India and balance is imported from other countries. Most of the plastics are recycled and sometimes it is not done so due to lack of sufficient market value. Of the waste plastic snot recycled about $43 \%$ is polyethylene and most of them is in the form of containers and packaging materials (Mani et al., 2009).

As the oil based plastic is the polymeric material, the plastic pyrolysis process is the thermal de-polymerization process without oxygen which can change over plastic into fuel range hydrocarbons (Williams and Williams, 1997). The waste plastic utilized as a part of pyrolysis process is should be cleaned and dried, then processed from an autoclave pyrolysis reactor. The temperature used in this process to obtain the plastic oil could be between $300-$ $500^{\circ} \mathrm{C}$ at atmospheric pressure and time required about 3-4 hours. The products yield comprises of $60-80 \%$ pyrolysis oil, $5-10 \%$ wax deposit and the rest is pyrolysis gas on weight premise (Demirbas, 2004). The plastic pyrolysis oil utilized as a part of this exploration is prepared from a business squander plastic pyrolysis plant in India. 


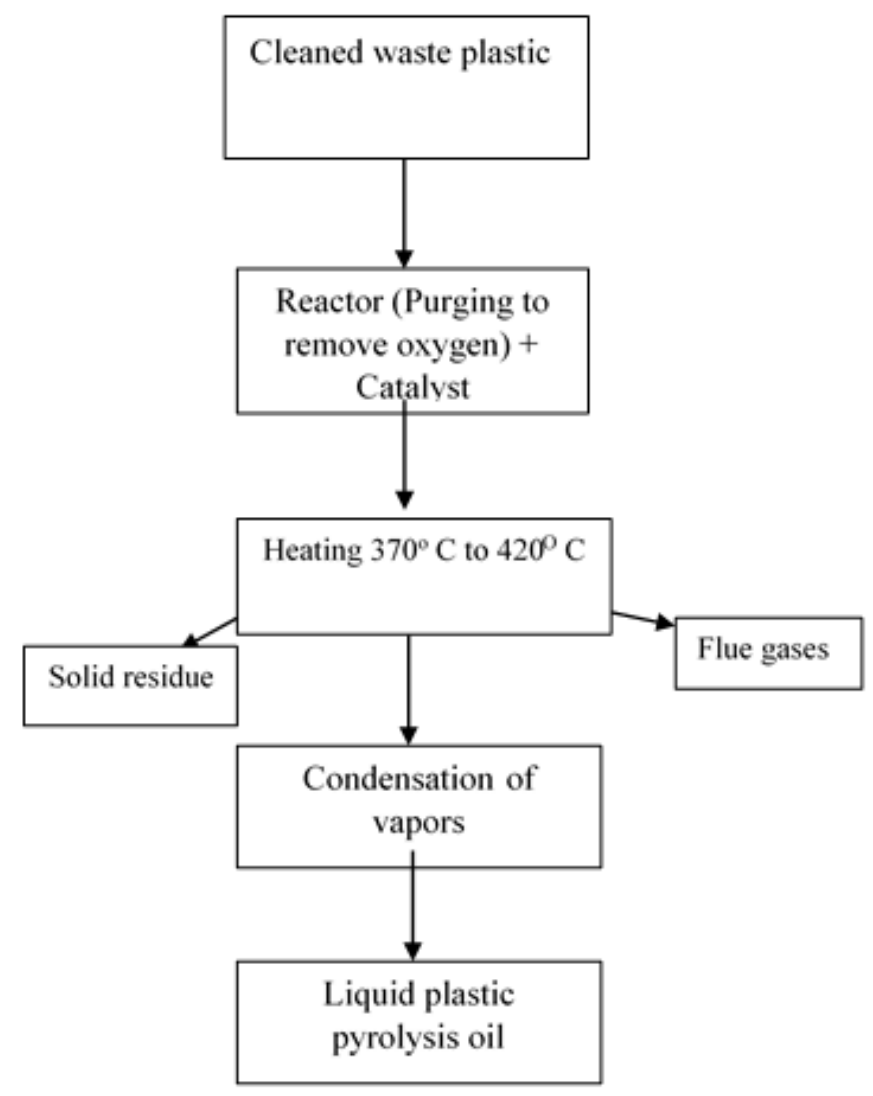

Figure 1. Process flowchart of Plastic pyrolysis oil

Table 1. Fuel properties

\begin{tabular}{lccc}
\hline Property & Method & Diesel & PPO \\
\hline Density $\left(\mathrm{kg} / \mathrm{m}^{3}\right)$ & ASTM D-4052 & 819 & 835.5 \\
\hline Kinematic viscosity $(\mathrm{cst})$ & ASTM D-445 & 2.94 & 2.52 \\
\hline Dynamic viscosity $\left(\mathrm{Ns} / \mathrm{m}^{2}\right)$ & ASTM D-7042 & 0.0020 & 0.0021 \\
\hline Flash point $\left({ }^{\circ} \mathrm{C}\right)$ & ASTM D-9390 & 57 & 46 \\
\hline Fire point $\left({ }^{\circ} \mathrm{C}\right)$ & ASTM D-9390 & 64 & 54 \\
\hline Calorific value $(\mathrm{kJ} / \mathrm{kg})$ & ASTM D-2015 & 44189 & 40248 \\
\hline Cloud point $\left({ }^{\circ} \mathrm{C}\right)$ & ASTM D-4052 & 2 & 4 \\
\hline Pour point $\left({ }^{\circ} \mathrm{C}\right)$ & ASTM D-2500 & -16 & $\leq-11$ \\
\hline Cetane number & ASTM D-613 & 52 & 46 \\
\hline Carbon residue $\%$ & ASTM D-524 & 0.35 & 0.21 \\
\hline
\end{tabular}

\section{Production of Plastic Pyrolysis Oil}

The feedstock consists of composite plastic of styrene butadiene and polyester type of plastic. This feedstock is cut into small pieces of approximately $5 \mathrm{~cm}^{3}$. It is then transferred to a closed chamber and purging is carried out in order to remove oxygen from the chamber. To make the reactor free from air, inert gas such as carbon dioxide or nitrogen gas is passed. Heating is provided from the external source, when the temperature inside the chamber is reached to $420^{\circ} \mathrm{C}$, plastics are converted into wax and gas. The wax is collected separately and gas is allowed to pass through the condenser. This gas gets condensed and collected in separate chamber. This liquid is further treated to reduce the chlorine content by using catalysts such as activated bentonite, red mud, and zeolites etc. Further it is filtered with $1 \mu \mathrm{m}$ filter paper. The oil obtained is called as PPO. Flow chart for the above process is shown in Figure 1.

Locally available diesel fuel was used for the study from Indian oil outlet and its properties are provided in Table 1. The properties of PPO and base fuels are tabulated in Table 1 based on as per values of ASTM standards.

\section{Effect of Injection Timing}

In the diesel engine, combustion and emission attributes are significantly impacted by the nature of atomization and specifically by the fuel-air blend show in the ignition chamber. IT and IOP are the most critical parameters influencing the diesel engine execution with various fuels (Gajendra Babu, 2007). Impeded fuel IT demonstrated noteworthy decrease in diesel NOx and bio diesel NOx (Hountalas et al., 2001; Tao et al., 2005). When there is 
Table 2. Engine specification

\begin{tabular}{cll}
\hline SI No & Parameters & Specification \\
\hline 1 & Type of engine & Kirloskar make Single cylinder four stroke direct injection diesel engine \\
\hline 2 & Nozzle opening pressure & 200 to 205 \\
\hline 3 & Rated power & $5.2 \mathrm{KW}(7 \mathrm{HP}) @ 1500 \mathrm{RPM}$ \\
\hline 4 & Cylinder diameter (Bore) & $87.5 \mathrm{~mm}$ \\
\hline 5 & Stroke length & $110 \mathrm{~mm}$ \\
\hline 6 & Compression ratio & $17.5: 1$ \\
\hline
\end{tabular}

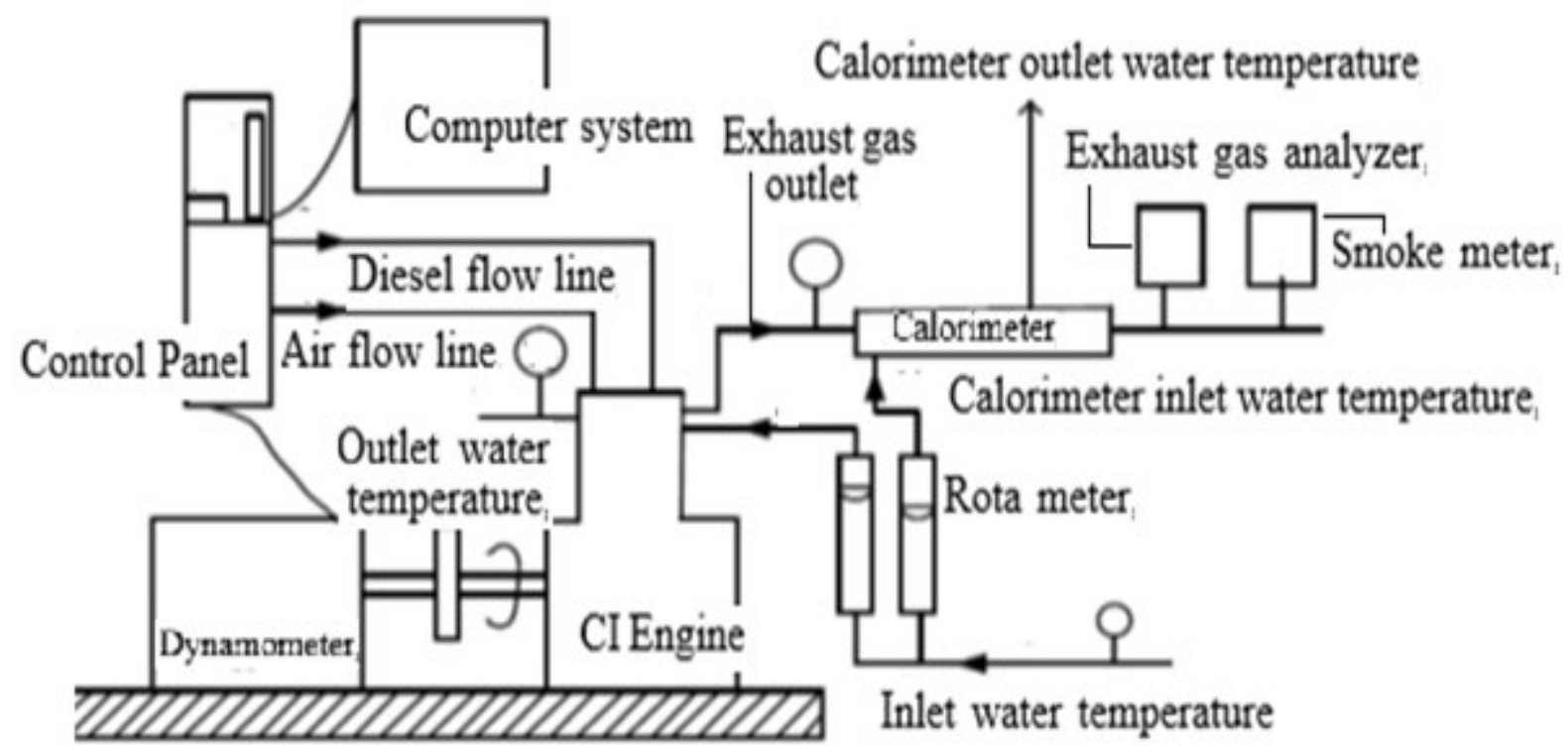

Figure 2. Schematic of the experimental setup

retard in the IT a gradual decrease in the cylinder pressures and temperatures were observed (Roy, 2009). The impact of fuel IT on CI engine fueled with waste cooking oil as an alternative has been investigated with IT advancement of $40^{\circ}$ bTDC and showed that improved efficiency, CO reduction and increased NOx emissions (Bari et al., 2004). In the literature (Banapurmath and Tewari, 2008), retardation in IT and increase in injection pressure shown improved performance using the fuel Honge biodiesel in the diesel engine application. Performance found better with high peak cylinder pressure and temperature at higher IOP (Banapurmath and Tewari, 2008; Rosli and Semin, 2008; Puhan Sukumar Jegan et al., 2009; Suresh et al., 2013).

I. From the available literature, it is acknowledged that very little work is available on engine with PPO as fuel. Present study investigates the thermal performance, emission and combustion characteristics of CI engine using PPO for various IT.

\section{EXPERIMENTAL SETUP}

Trials were led on a Kirloskar TV1 type CI engine. Figure 2 demonstrates the outline of the test rig utilized and engine detail is shown in Table 2. Engine was loaded with the help of eddy current dynamo-meter. The Rate of fuel flow was measured with the help of burette and stopwatch on volumetric basis. The engine speed was 1500 rpm always. HARTRIDGE smoke meter was utilized to measure the smoke and five gas analyzer for steady state condition.

\section{ENGINE PERFORMANCE RESULT}

The test consequence of the engine execution demonstrates the chance of utilizing pyrolysis oils in $\mathrm{CI}$ engine. The variation of the IT with the break power shown revealed that the thermal efficiency of the PPO is similar to diesel. IT considered for the analysis were of $19^{\circ}, 23^{\circ}, 27^{\circ}$ and $31^{\circ} \mathrm{BTDC}$, while pressure was maintained constant of 205 bar. Four readings were taken and averaged to plot graphs and IT was optimized.

\section{Effect of IT on BTE}

Figure 3 represents the effect of IT on BTE for diesel and PPO. It can be observed from the results that the BTE of PPO was lower than the diesel. This may due to lower heating value and higher viscosity of PPO. However, 


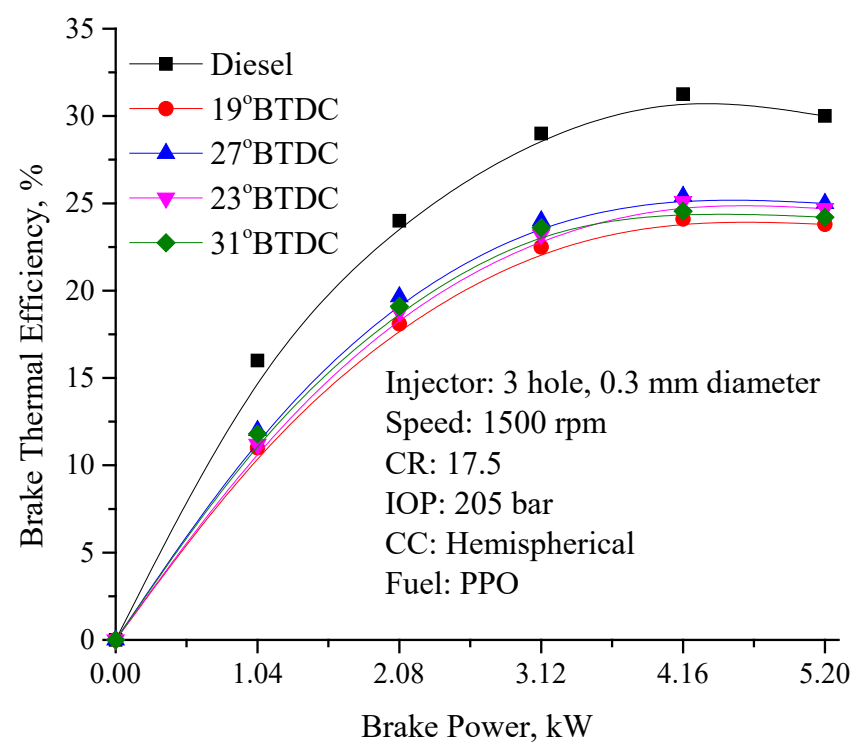

Figure 3. Effect of IT on BTE

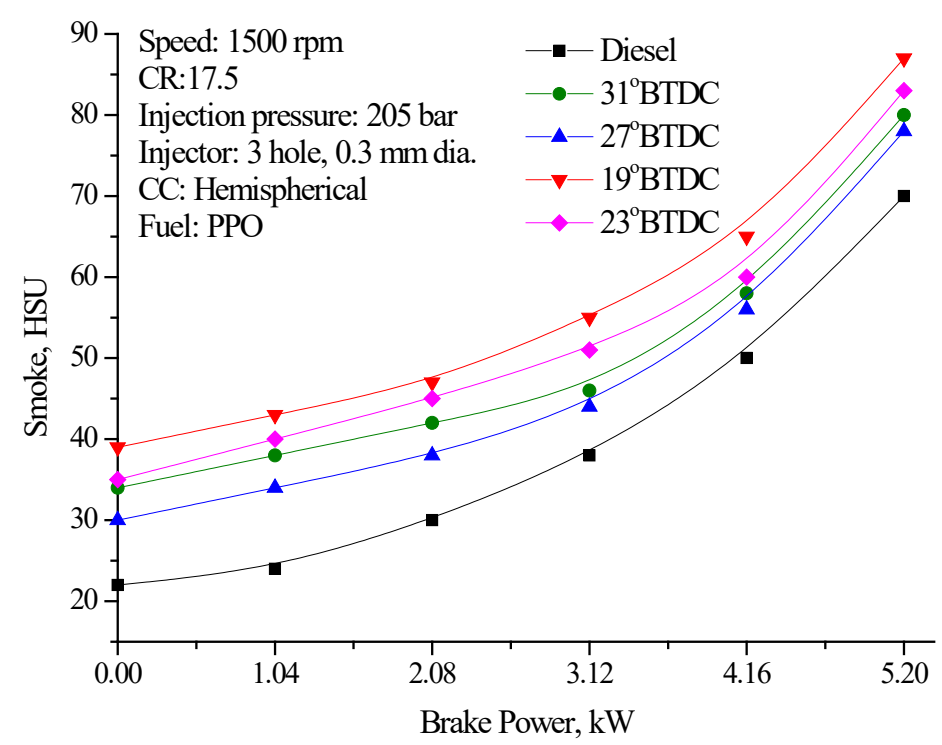

Figure 4. Effect of IT on smoke opacity

when the IT was varied, an improvement in the BTE of PPO was observed and found maximum at IT $27^{\circ} \mathrm{bTDC}$. On advancing, the time availability of fuel mixing with air and combustion will increase. This will lead to better combustion process and hence improved BTE. However, further advancement of IT, lower BTE was observed.

\section{Effect of IT on Smoke Opacity}

Figure 4 shows the impact of IT on Smoke Opacity of diesel engine. For all IT, Smoke was found to be more in case of PPO than diesel and for IT of $27^{\circ} \mathrm{C}$, lower value was observed. This may be due to higher molecules of $\mathrm{HC}$ and particulate associated in PPO. One more reason may higher viscosity of PPO.

\section{Effect of IT on HC and CO Emissions}

Figure 5 depicts the effect of IT on HC emissions of PPO and diesel. It was observed that the engine fuelled with PPO, HC emission was found higher than diesel which may be due to poor spray behavior of PPO that led to poor mixing and poor combustion. Compared to all IT, lower HC emission was found for an IT of $27^{\circ} \mathrm{bTDC}$. $\mathrm{CO}$ also showed similar trend as that of $\mathrm{HC}$ and found better at IT of $27^{\circ} \mathrm{bTDC}$. 


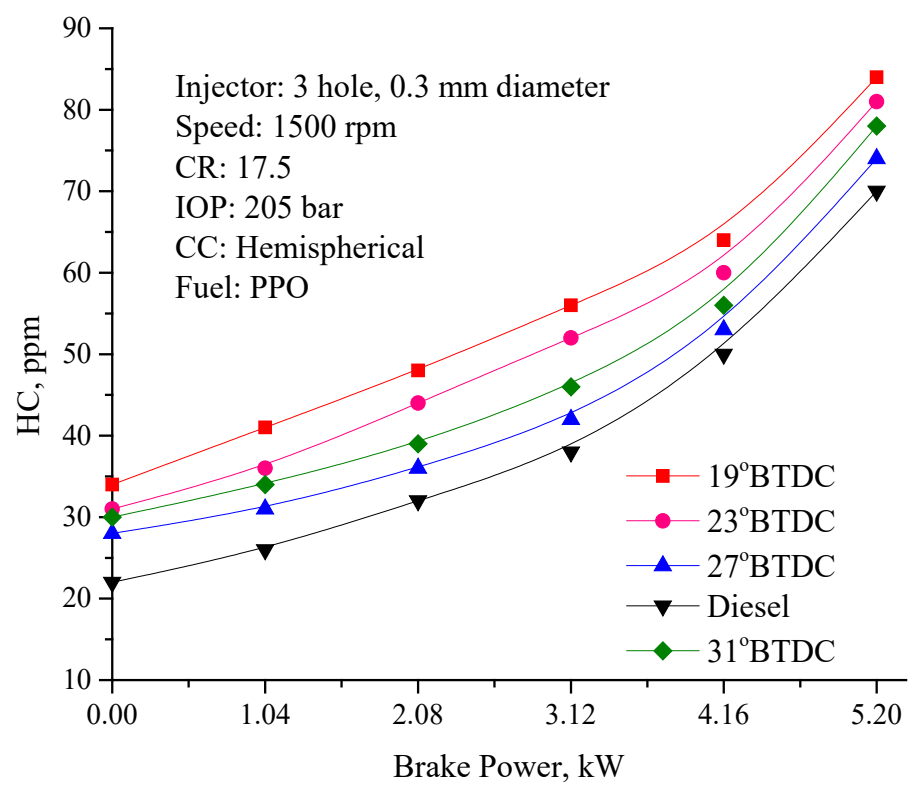

Figure 5. Effect of IT on HC

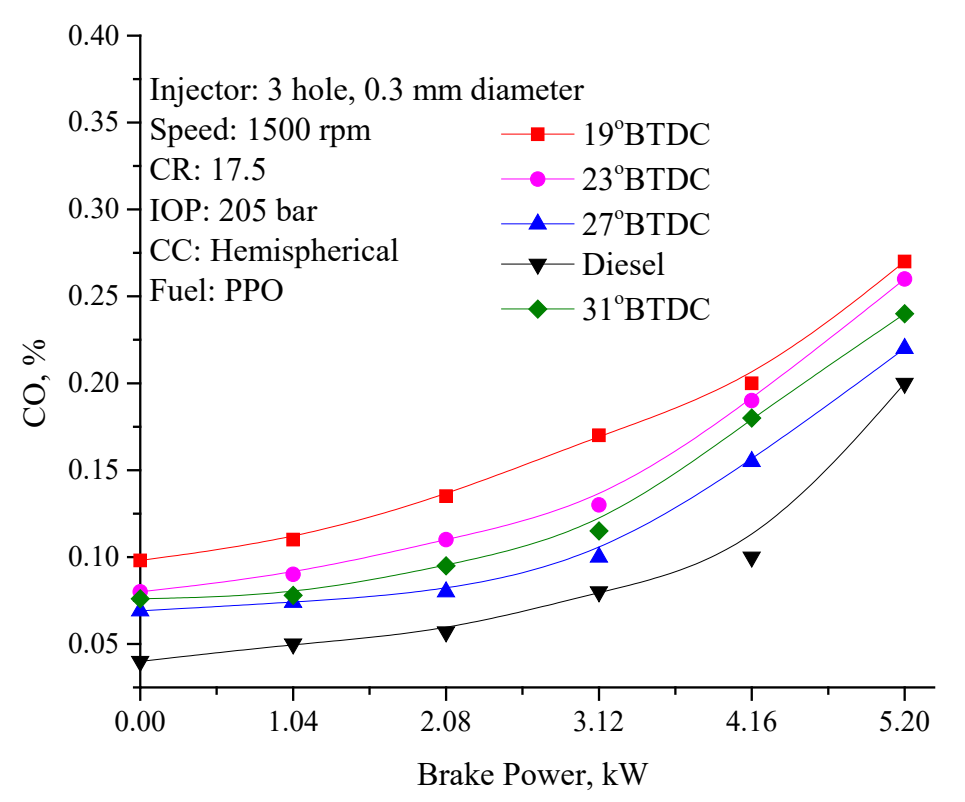

Figure 6. Effect of IT on CO

\section{Effect of IT on NOx Emissions}

The main factors responsible for NOx formation are increased temperature, oxygen availability and residual time. A significant reduction in NOx emissions was observed with reduction in IT.

On retarding the IT, the combustion process gets reduced. As the IT is retarded, the combustion process gets retarded. NOx was found lower for IT of $19^{\circ} \mathrm{bTDC}$ for PPO and found more NOx emissions for all IT. As peak temperature was lower at retarded IT, NOx was found to lower.

From the experimental results it can be seen that the injection timing of $27^{\circ}$ BTDC (static) is the optimum for PPO as the BTE increased while smoke, HC and $\mathrm{CO}$ emissions were lower at this IT.

\section{Effect of IT on Peak Pressure}

Figure 8 represents, the effect of injection timing for Peak pressure of diesel engine fuelled with PPO and diesel. The cylinder pressure - crank angle history was acquired for 100 cycles and the averaged peak pressure was 


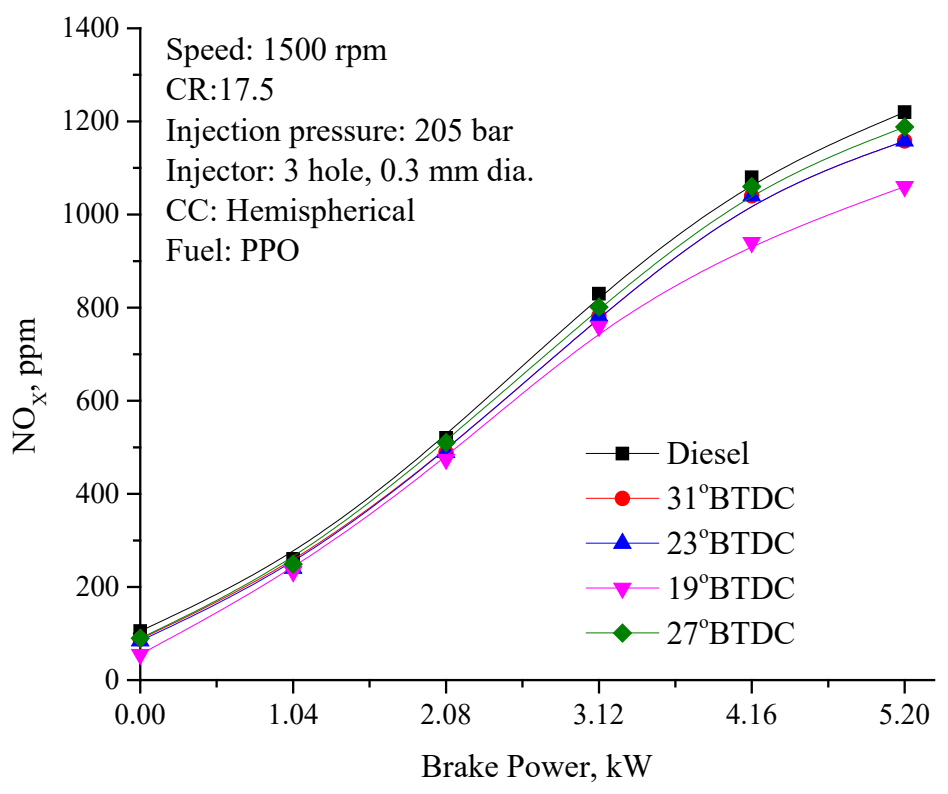

Figure 7. Effect of IT on NOx

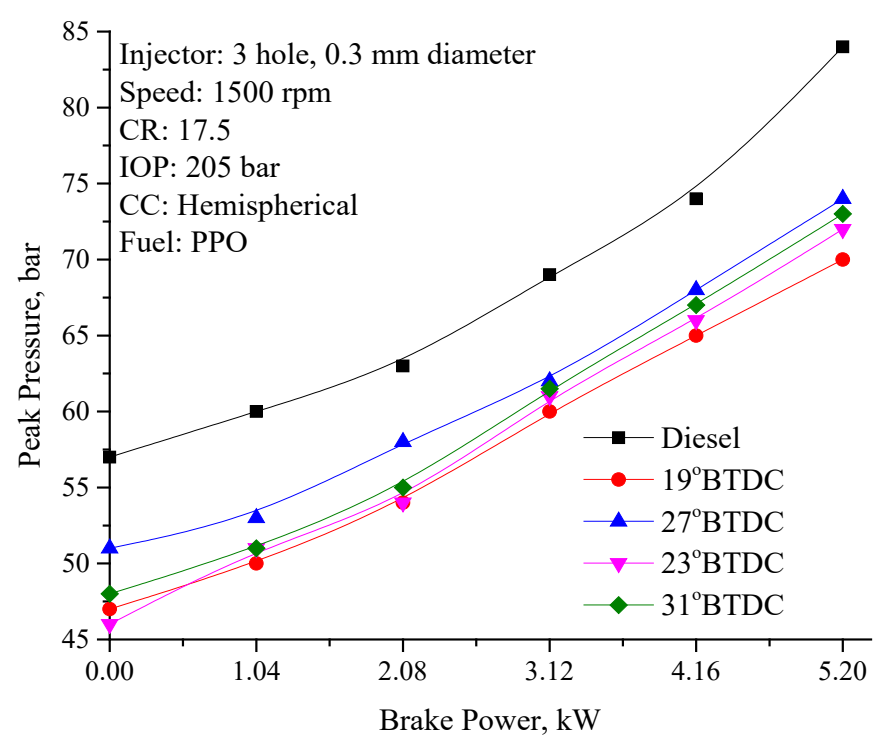

Figure 8. Effect of IT on PP

used to plot graphs at all loads. For all IT, PP was low for all IT when PPO was used as a fuel. This may be due to its lower energy content. It may be due to the combined effect of longer ignition delay (ID), lower adiabatic flame temperature and slower burning rate of the PPO.

\section{Ignition Delay}

Ignition delay decreases with the advancement of IT for PPO as shown in Figure 9. The ID is calculated based on the static IT using pressure crank angle history for 100 cycles. As compared to diesel, the ID was more in case of PPO for all IT. The viscosity and density of the PPO was marginally high compared to diesel could be the reason for the longer ID. On advancement of IT, the ID decreased and found minimal at IT $27^{\circ} \mathrm{bTDC}$. On advancing the IT, BTE was improved due to ID reduction.

\section{Combustion Duration}

Variation in CD with IT shown in Figure 10 was calculated based on the duration between the start of combustion (SOC) and 90\% cumulative heat release. The total CD is the period of the overall burning process and 


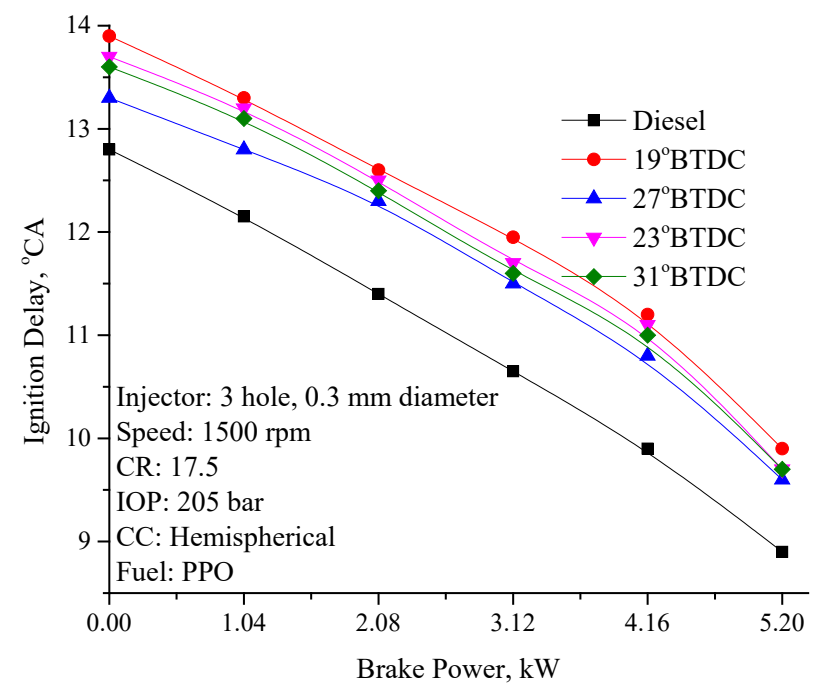

Figure 9. Effect of IT on ID

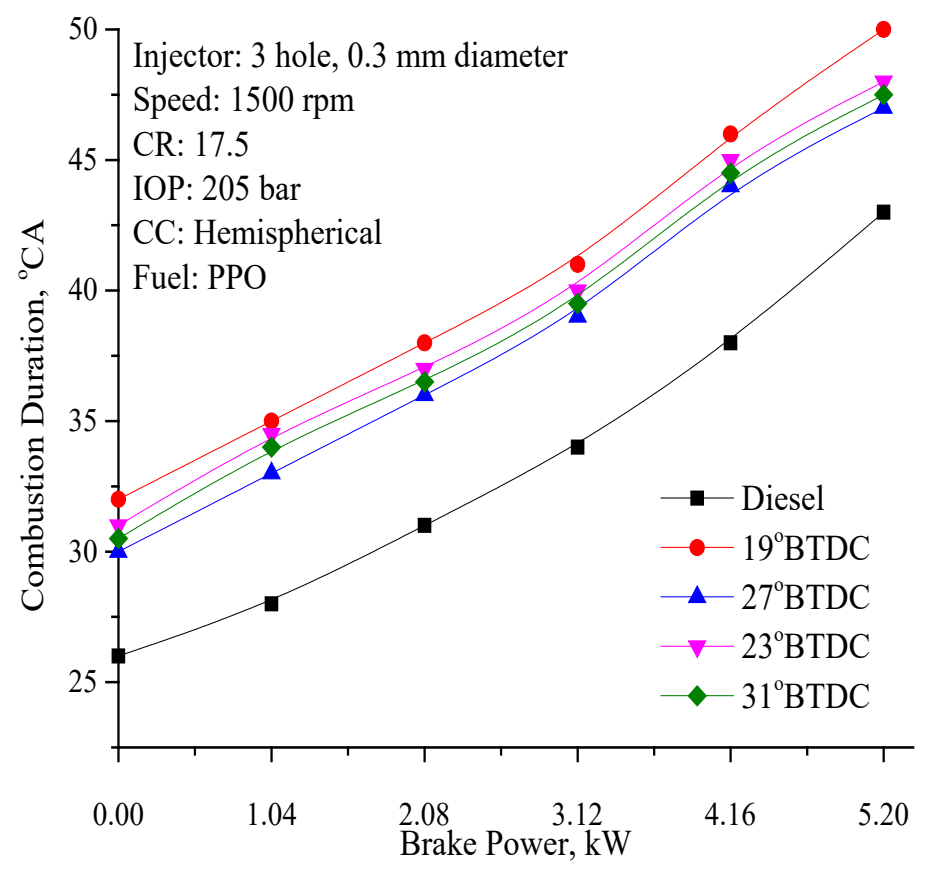

Figure 10. Effect of IT on Combustion Duration

it is the sum of flame development period and rapid combustion period. Higher CD was observed for PPO compared to diesel operation. It might be due to higher viscosity of PPO led to improper air-fuel mixing, lower gas temperature and pressure. However $\mathrm{CD}$ was reduced with increase in IT and found minimal at $27^{\circ}$ BTDC all loads. This could be attributed to the amount of fuel being burnt inside the combustion chamber gets increased.

\section{Heat Release Rate}

Figure 11 represents the HRR of PPO under effect of IT. Effect of IT on HRR at $80 \%$ load is given in Figure 12 for PPO and diesel. It found maximum at IT $27^{\circ}$ bTDC. It was observed from the result, HHR was lower in case of PPO than the diesel. Lower calorific value of the fuel could the reason for such condition. On variation of IT, an improvement in the HRR was observed as ID lowered and CD also improved due which the HRR improves at IT $27^{\circ}$ bTDC.

The cumulative heat release values, which is the aggregate sum of instantaneous HRRs is given in Figure 13. This curve has the characteristic $S$ shape. The HRR was slow at the beginning and increases rapidly till reaching a 


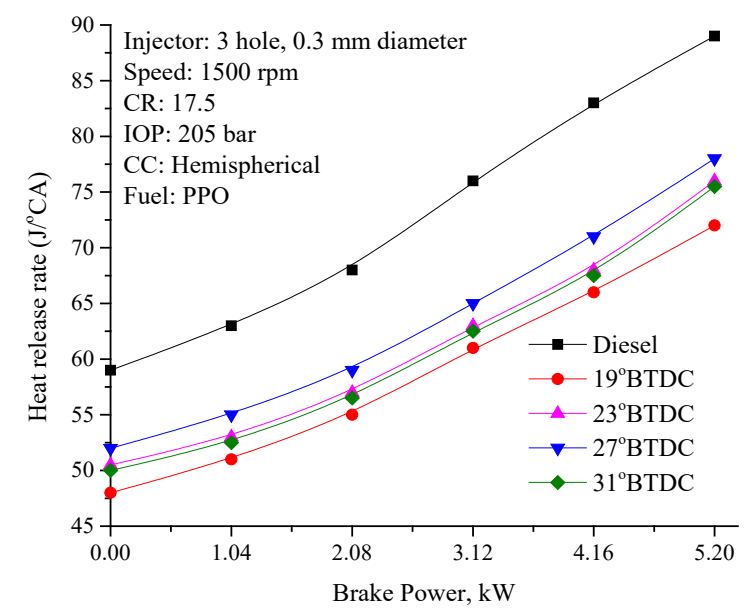

Figure 11. Effect of IT on HRR

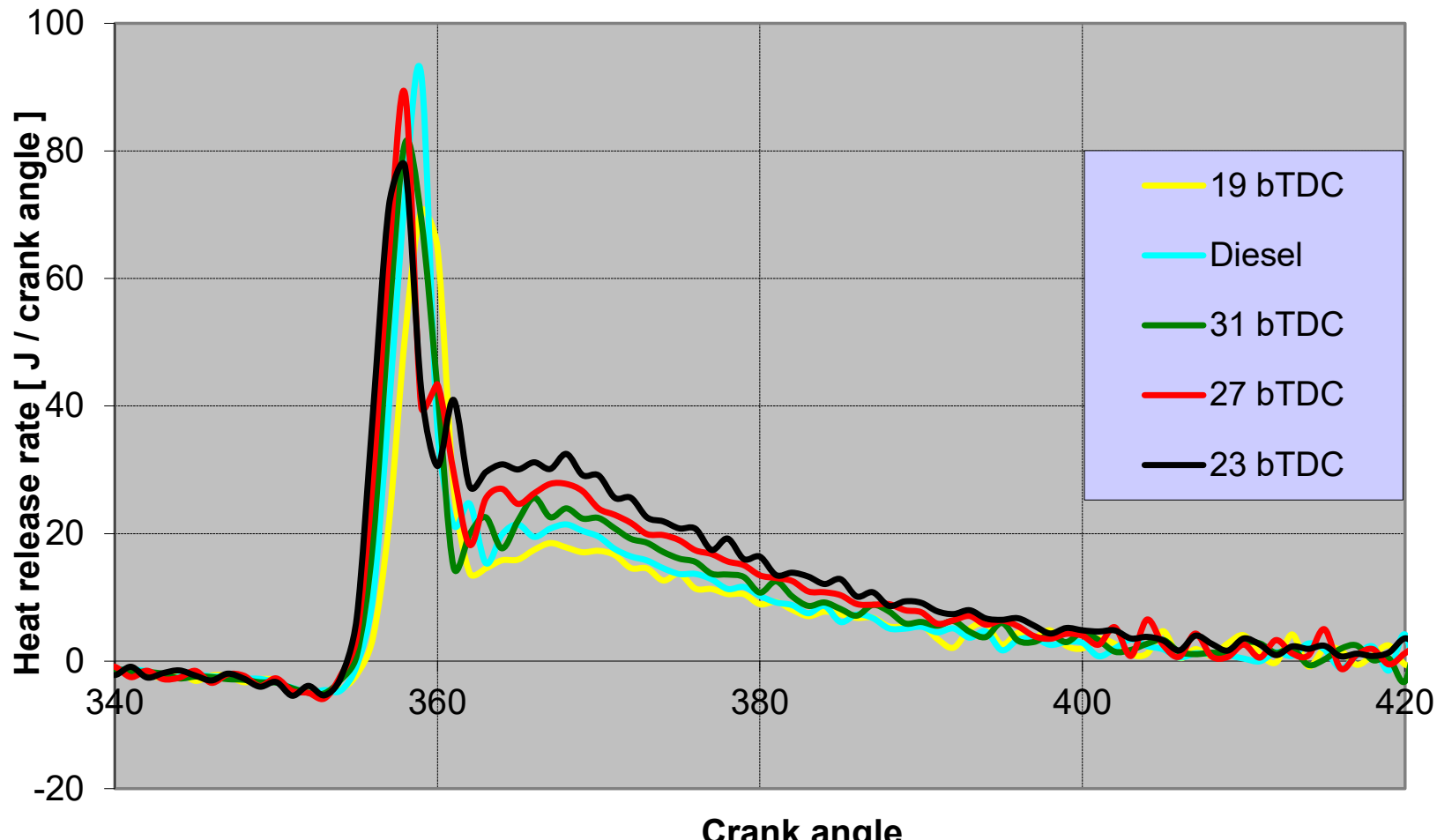

Figure 12. Variation in HRR with crank angle at different fuel IT at $80 \%$ load

peak value then again slows down. This is reflected in Figure 13, where the cumulative release value is low in the beginning, increases exponentially and slows down at the end. The maximum cylinder pressure occurs at $46^{\circ}$ aTDC, nearly $10^{\circ}$ after the occurrence of maximum heat release rate. At the time of maximum pressure, nearly $80 \%$ of the heat was released as seen in Figure 13.

\section{Brake Specific Fuel Consumption (BSFC)}

The weight of fuel burned per hour to produce a given amount of brake power in a diesel engine is known as BSFC. BSFC variation with Brake power at different IT has been provided in Figure 14. It was minimum at 80\% load at all IT selected due to better combustion. However for PPO it was lower compared to diesel operation.

\section{CONCLUSIONS}

From the comprehensive examination, it has been observed that the execution of the diesel Engine utilizing PPO varying with advance timing indicated change in BTE, when IT was progressed. The accompanying conclusion exhibited: 


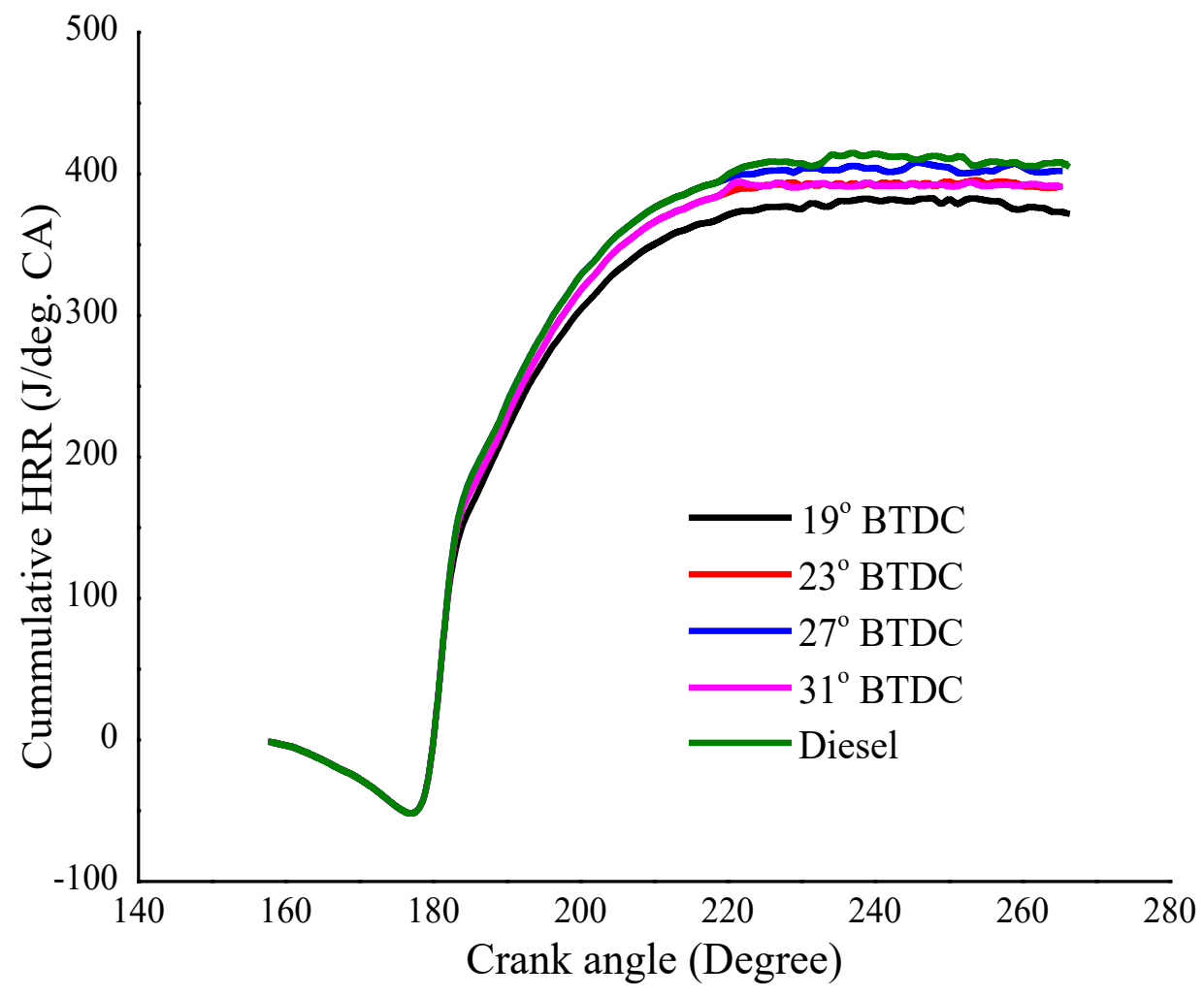

Figure 13. Effect of IT on Cumulative HRR at $80 \%$ load

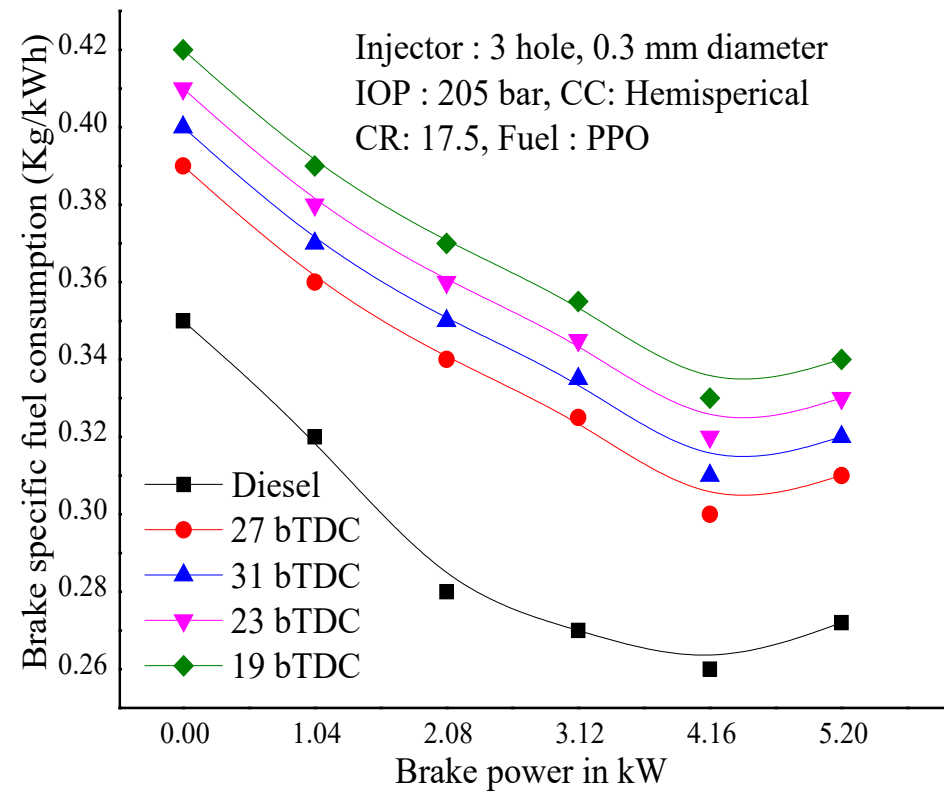

Figure 14. Effect of IT on BSFC

- Energy from waste solid can be reutilized as substitute to the conventional fuel.

- BTE of PPO was observed poor with manufacturer specification because lower heating value and high viscous of the fuel. However, when the injection timing varied the variation in BTE was observed and found to be improved and higher at IT of $27^{\circ} \mathrm{bTDC}$ for engine as compared to other IT. 
- The smoke emission of PPO was higher than diesel, but as IT was varied there was decrease in the emission at $27^{\circ}$ bTDC.

- $\mathrm{HC}$ and $\mathrm{CO}$ were high for the selected fuel. On the other hand, varying the IT these emission were minimized to certain extent and compared to different IT, $27^{\circ}$ BTDC showed better results.

- NOx emissions was found in increasing trend with advancement of IT

- Cylinder peak pressure was found to lower for PPO than diesel. On advancement of IT, improvement in PP was observed.

- ID for PPO was more than the diesel because of poor atomization of selected fuel. However at $27^{\circ} \mathrm{BTDC}$, improvement of ID was observed.

- $\quad \mathrm{CD}$ for PPO was more compared to diesel, because of higher viscosity of the fuel and amount fuel injected was more compared to diesel.

It can be concluded that with minor modification in injection strategy of IT, PPO can be utilized to operate the diesel engine and act as alternative fuel to substitute the diesel and further investigation can be done by varying the injector opening pressure along blend of PPO with other biofuel to reduce the NOx.

\section{NOMENCLATURE}

PPO Plastic pyrolysis oil

bTDC before Top Dead Centre

BTE Brake Thermal Efficiency

CC Combustion Chamber

CR Compression Ratio

CO Carbon Monoxide

HC Hydrocarbon

ID Ignition Delay

IP Injection Pressure

IOP Injection Opening Pressure

IT Injection Timing

NOx Oxides of Nitrogen

PM Particulate Matter

SOC Start of Combustion

SOI Start of Injection

\section{REFERENCES}

Banapurmath, N. R. and Tewari, P. G. (2008). Combustion and emission characteristics of a Direct Injection CI engine when operated on Honge oil, Honge oil methyl ester (HOME) and blends of Honge oil methyl ester (HOME) and diesel. International Journal of Sustainable Engineering, Francis and Taylor Publications, 1, 80-93. https://doi.org/10.1080/19397030802221265

Bari, S., Yu, C. W. and Lim, T. H. (2004). Effect of fuel injection timing with waste cooking oil as a fuel in direct injection diesel engine. Proc. Instn. Mech. Engrs. IMechE, Part D, Journal of Automobile Engineering, 218, 93-104. https://doi.org/10.1243/095440704322829209

Demirbas, A. (2004). Pyrolysis of Municipal Plastic Wastes for Recovery of Gasoline-Range Hydrocarbons. Journal of Analytical and Applied Pyrolysis, 72, 97-102. https://doi.org/10.1016/j.jaap.2004.03.001

Gajendra Babu, M. K. (2007). Studies on performance and exhaust emissions of a CI engine operating on diesel and diesel biodiesel blends at different injection pressures and injection timings. Society of Automotive Engineers, Paper No: 2007-01-0613.

Hamid, S. H., Amin, M. B. and Maadhah, A. G. (1992). Handbook of Polymer Degradation, Marcel Decker, New York.

Hountalas, D. T., Kouremenos, D. A., Binder, K. B., Raab, A. and Schnabel, M. H. (2001). Using advanced Injection timing and EGR to Improve DI engine efficiency at Acceptable NO and Soot levels. Society of Automotive Engineers, Paper No: 2001-01-0199.

Islam, M. R., Joardder, M. U. H., Hasan, S. M., Takai, K. and Haniu, H. (2011). Feasibility Study of Thermal Treatment of Solid Tire Wastes in Bangladesh by Using Pyrolysis Technology. Waste Management, 31, 21422149. https:// doi.org/10.1016/j.wasman.2011.04.017 
Lin, C. Y. and Wang, K. H. (2004). Effects of diesel engine speed and water contents on emission characteristics of three phase emulsions. Journal of Environmental science and Health, 39, 1341-1355. https://doi.org/10.1081/ESE-120030336

Mani, M. and Nagarajan, G. (2009). Influence of Injection Timing on Performance, Emission and Combustion Characteristics of a DI Diesel Engine running on Waste Plastic Oil. Energy, 34, 1617-1623. https://doi.org/10.1016/j.energy.2009.07.010

Mani, M., Subash, C. and Nagarajan, G. (2009). Performance, Emission and Combustion Characteristics of a DI Diesel Engine Using Waste Plastic Oil. Applied Thermal Engineering, 29, 2738-2744. https:// doi.org/10.1016/j.applthermaleng.2009.01.007

Mani, M., Nagarajan, G. and Sampath, S. (2011). Characterisation and Effect of Using Waste Plastic Oil and Diesel Fuel Blends in Compression Ignition Engine. Energy, 36, 212-219. https://doi.org/10.1016/j.energy.2010.10.049

Murugan, S., Ramaswamy, M. C. and Narajan, G. (2008). Performance, Emission and Combustion Studies of a DI Diesel Engine Using Distilled Tyre Pyrolysis Oil-Diesel Blends. Fuel Processing Technology, 89, 152-159. https://doi.org/10.1016/j.fuproc.2007.08.005

Phong, H. V., Osami, N., Hirotsugu, F., Wataru, H., Norihiko, T. and Masami, I. (2001). Reduction of NOx and PM from diesel engines by WPD emulsified fuel. SAE Technical Paper 2001-01-0152.

Puhan Sukumar Jegan, R., Balasubbramanian, K. and Nagarajan, G. (2009). Effect of injection pressure on performance, emission and combustion characteristics of high linolenic linseed oil methyl ester in a DI Diesel engine. Renewable Energy, 34, 1227-1233. https://doi.org/10.1016/j.renene.2008.10.001

Rogers, J. G. and Brammer, J. G. (2012). Estimation of the Production Cost of Fast Pyrolysis Bio-Oil. Biomass and Bioenergy, 36, 208-217. https://doi.org/10.1016/j.biombioe.2011.10.028

Rosli, A. and Semin, A. I. (2008). Fuel injection pressure effect on performance of direct injection diesel engines based on experiment. American Journal of Applied Sciences, 5, 197- 202. https://doi.org/10.3844/ajassp.2008.197.202

Roy, M. M. (2009). Effect of fuel injection timing and injection pressure on combustion and odorous emissions in DI diesel engine. Journal of Energy Resources Technology, ASME Transactions, 131, 1-8. https:// doi.org/10.1115/1.3185346

Rutz, D. and Janssen, R. (2007). Biofuel Technology Handbook. WIP Renewable Energies.

Scheirs, J. and Kaminsky, W. (2006). Feedstock Recycling and Pyrolysis of Waste Plastics: Converting Waste Plastics into Diesel and Other Fuels. John Wiley \& Sons Ltd., Chichester. https:// doi.org/10.1002/0470021543

Suresh, G., Kamath, H. C. and Banapurmath, N. R. (2013). Effect of Injection timing, Injector opening pressure and Nozzle geometry on the performance of Cotton seed oil methyl ester fueled diesel engine. International Journal of Sustainable Engineering, Francis and Taylor Publications, 7, 82-92.

Tao, F., Liu, Y., Rempel Ewert, B. H., Foster, D. E., Reitz, R. D., Choi, D. and Miles, P. C. (2005). Modelling the effect of EGR and retarded injection on soot formation in a high speed diesel injection (HSDI) diesel engine using a multi-step phenomenological soot model. Society of Automotive Engineers, Paper No: 2005 -01-0121.

U.S.EPA. (2010). Municipal Solid Waste Generation, Recycling, and Disposal in the United States Tables and Figures for $2010 . \quad$ Available at: http://www.epa.gov/osw/nonhaz/municipal/pubs/2010_MSW_Tables_and_Figures_508.pdf (Accessed January 2013).

Williams, P. T. and Williams, E. A. (1990). Interaction of plastics in mixed plastics pyrolysis. Energy and Fuels, 13, 188-196. https://doi.org/10.1021/ef980163x

Williams, E. A. and Williams, P. T. (1997). Analysis of Products Derived from the Fast Pyrolysis of Plastic Waste. Journal of Analytical and Applied Pyrolysis, 40-41, 347-363. https:/ / doi.org/10.1016/S0165-2370(97)00048-X 